\title{
Structural features of metal powders obtained by plasma spraying
}

\author{
Evgeny Gulikhandanov ${ }^{1}$, Sergey Ermakov ${ }^{2}$ \\ ${ }^{1}$ Doctor of Engineering Science, Professor of the Institute of Mechanical Engineering, Materials and Transport SPbPU \\ Saint Petersburg, Peter the Great St.Petersburh Politechnic University, RU-195251, St.Petersburg, Russia \\ ${ }^{2}$ Engineer, Director of Scientific and Educational Center «Severstal-Politech» Saint Petersburg, Peter the Great \\ St.Petersburh Politechnic University, RU-195251, St.Petersburg, Russia
}

\begin{abstract}
The development of additive technologies in the Russian Federation is constrained by the lack of indigenous base for the production of metal powders. SPbPU has developed, manufactured and introduced a plasma atomizer. It provides atomization of metal powders and alloys of various chemical compositions. The data on the main technological parameters of atomization of nickel alloy Inconel 718 and titanium alloy Ti-6A1-4V are presented in the paper. It is shown that by optimizing the spraying mode the possibility to obtain alloy powders with a high level of sphericity and a minimum number of particles with surface and internal defects. The chemical compositions of the obtained particles are almost identical to the composition of the initial atomized materials. Samples for the mechanical testing were made from the obtained powders by the SLM method. The results of mechanical properties tests show that the properties of samples made by 3D printing methods from powders sprayed by plasma atomization methods are identical to the properties of materials made and heat-treated by traditional methods.
\end{abstract}

\section{Introduction}

The beginning of the XXI century was marked by the development of new approaches and requirements for manufactured equipment. The most popular technologies of the past - technologies based on subtractive processing processes, such as turning, milling, and drilling - are becoming a thing of the past. Using subtractive technologies caused the metal utilization rate to reduce - more than half of the billet mass was consumed in the chips. Moreover, significant human and energy resources were spent. Subtractive technologies are being replaced by new - additive technologies based on prototyping parts by laser fusing of metal powders. These technologies can reduce the material consumption of products by two or more times, simplify the technological process of their production, and solve environmental safety issues.

Nowadays additive technologies are among the fastest growing technological processes - the annual growth rate of the use of $3 \mathrm{D}$ printing reaches, and in some years exceeds $20 \%$. At the beginning of the century, the Russian Federation had the development rate of additive technologies was at the level of the highest world indicators. However, in the last decade, the intensity of development of additive technologies in the Russian Federation is gradually slowing down. One of the main reasons for this slowdown is the virtual absence of the indigenous production base of raw materials for additive machines i.e. metal powders.
Currently, more than $70 \%$ of the required amount of metal powders are supplied from abroad i.e. the countries of the European Union, Canada, the United States and China. [1,2] However, the policy of sanctions imposed on our country by a number of Western countries, makes it difficult to obtain the necessary volume of powder product.

Despite the difficulties that have arisen in the Russian Federation, there is a steady demand for both additive machines and raw materials for the production using 3D printing methods. The main consumers of additive products in the Russian Federation are the most high-tech industries: aircraft and shipbuilding, space, medicine, and energy engineering. There has been the most common distribution of additive technologies in the experimental and experimental-industrial developments of these industries. These industries require production of one or more experimental products in the shortest possible time and conduct their accelerated tests. In these industries, additive prototyping based on 3D models can significantly speed up and reduce the cost of introducing new machines and mechanisms into production, including eliminating the production of complex tooling (molds, dies, etc.) necessary for the production of a prototype.

In our view, the further expansion of additive manufacturing at domestic enterprises should be linked to phasing out of external suppliers of the powder product. First of all, this applies to the pilot plant production. The creation period of a prototype is comparable to the purchase period of the powder 
necessary for its production, and the creation of their own powder production facilities on the base of a plant. The powder production can rely on the plasma spraying of metal powders since the plasma spraying equipment is relatively cheap, does not require the allocation of specialized premises and highly qualified personnel. Currently, the Russian Federation has developed a number of plasma atomizers that fully meet the world level. These include atomizers designed and manufactured at Peter the Great St. Petersburg Polytechnic University. These atomizers are easily reconfigured for the powder production of various chemical and granulometric compositions (necessary for 3D printing), and have a high level of sphericity.

This paper presents the main technological parameters of the powder production of nickel - Inconel 718 and titanium - Ti-6Al-4V alloys and the research results of these powders, confirming the possibility of their use in additive machines of various types. The choice of materials was guided by the fact that these alloys are currently used as widely as possible in additive manufacturing. Due to the high stability of Inconel 718 mechanical properties at elevated temperatures this alloy is used extensively in gas turbines, jet engines, nuclear reactors and high-pressure vessels. Inconel 718 is used in oil and gas extraction and subsequent processing of raw hydrocarbon due to its high resistance in aggressive environments. However, in the application of this alloy, it is difficult to obtain products of complex shape. It happens due to its lowpressure workability because of extremely narrow temperature-speed range of plastic deformation and the complexity of mechanical processing due to the high tendency of this material to harden. One of the most effective manufacturing technologies for this alloy is the technology of layer-by-layer or direct laser fusing of powders in 3D printers [3].

The Ti-6Al-4V alloy is also widely used in products obtained by additive growing methods. It is used in products requiring the highest possible corrosion resistance and specific strength at a minimum density, so it is widely used in the aerospace industry, bioengineering, and medical technology.

\section{Materials and methods}

Plasma atomization is a kind of gas atomization in which the melting of a solid feedstock occurs under the influence of a high energy flow of ionized gas-plasma. Atomizers based on plasma atomization are the most compact and cheap systems for producing smallexperimental batches of powders of various chemical compositions. The advantages of plasma atomization include a high sphericity level of the obtained powders, the absence or minimum number of defects typical for 3D printer powders, such as internal and external pores, satellites, and oxide films on the surface of the particles. The disadvantages of plasma atomization include the low productivity of the process (usually from 1 to $10 \mathrm{~kg}$ of powder per hour), due to the characteristics of the starting materials for plasma atomization, which are usually used as wires with a diameter of 1 to 3-4 $\mathrm{mm}$ [46].

The atomizer developed at SPbPU (Fig.1) [7] consists of several interconnected blocks. The main units of the installation are powder spraying units, the number of which can vary from one to three according to the type and purpose of the atomizer. In turn, the spray units consist of plasma generators - plasma torches, wire feed systems and plasma gas. The current supplied to the plasma torch, the wire feed rate and the volume of plasma gas supply can be independently adjusted for each of the spray units.

This makes it possible, if necessary, for example, to obtain initial powders for mechanical alloying [8], to simultaneously spray wires of several chemical compositions.

Depending on the volume and composition of the powder required at the moment, spraying on such atomizer can be carried out either by one or simultaneously by three independently operating spray units - (Fig.2).

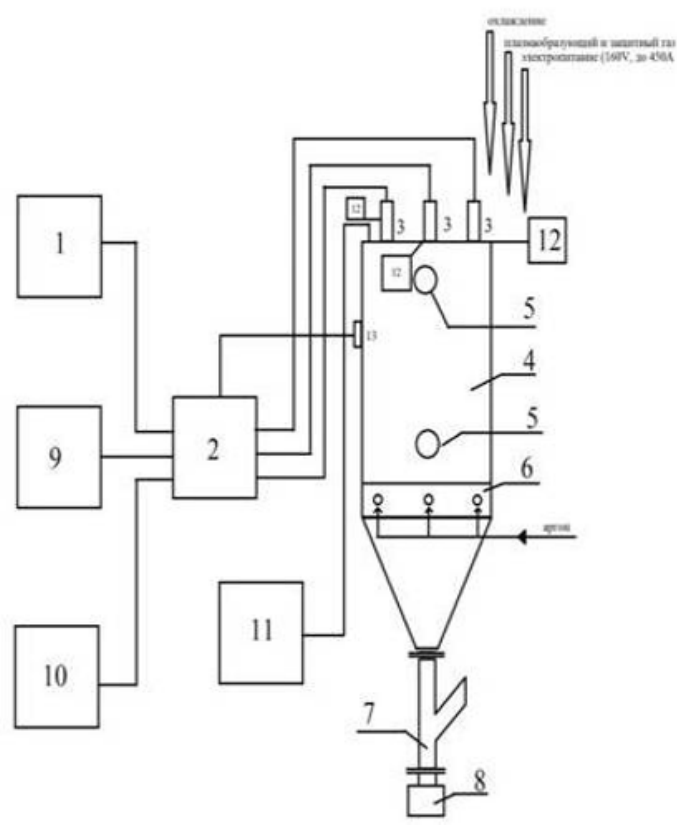

Fig. 1. Schematic circuit of a plasma atomizer: 1. Power supply, 2. Control and safety units, 3. Plasma torches (there is the layout of the atomizer with three spray units), 4. Spray column, 5. Peephole on the chamber side surface for visualizing the spray process, 6 . "Fluidized bed" belt - a system of multidirectional injectors through which protective gas is supplied, 7. Plasma gas removal system during the spray process, 8. Powder collection system, 9. Gas system, 10. Plasma torch cooling system, 11. Column cooling system spraying, 12. Solid feedstock supply system, 13. Measuring equipment (control and safety device).

The atomizer also includes a spray column (a twolayer water-cooled sealed vessel where the process of spraying spheroidization and crystallization of powder particles takes place), a powder collection system that allows the collection, packaging and storage of the sprayed powder without access to aggressive environmental components, water, gas and energy 
supply systems, spraying control process, equipment for supplying the initial feedstock, plasma-forming and protective gas.

The indicators that determines the efficiency and profitability of the atomizers operation are the following: the yield of useful (marketable) products, the stability of the geometric and granulometric characteristics of the sprayed powders. The paper presents the research results of the technological parameters effect of spraying on the percentage of commercial fractions yield of two alloys powders with high affinity for oxygen - Inconel 718 and Ti-6Al-4V. The data on the influence of the technological parameters of spraying on the geometric shape and granulometric composition of the sprayed powders are also presented.

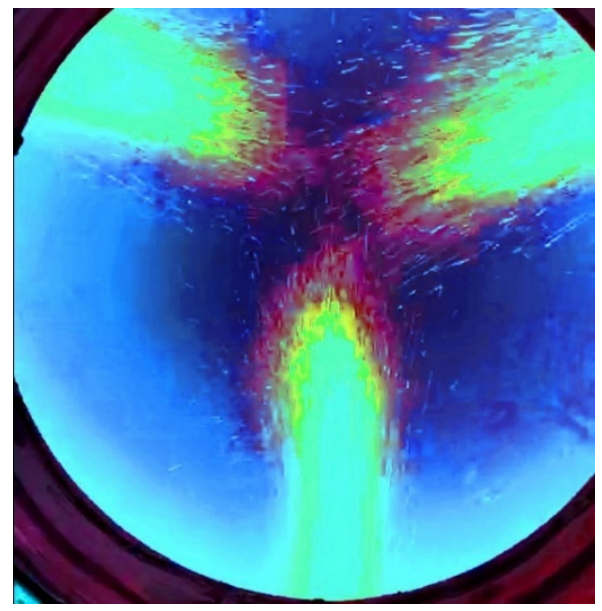

Fig. 2. Three independent powder spray torches - view through the peephole window in the upper bottom of the spray chamber.

During the experiments, the following sputtering parameters were varied: the current applied to the plasma torch in the range of 150-400 A, the speed (volume) of the plasma-forming gas - 30-60 l/ min, the wire feed speed - 1-5 $\mathrm{m} / \mathrm{min}$. As the constant factors of the experiments, the following factors were established: the flow rate of the protective gas $1.2 \mathrm{l} / \mathrm{min}$ per nozzle of the fluidized bed system and the gas temperature in the spray chamber determined by measuring the temperature on the inner wall of the spray chamber $-1050^{\circ} \mathrm{C}$. All experiments were carried out in the mode of simultaneous operation of three spray units operating in a single technological mode.

Wires of both alloys with a diameter of $1.8 \mathrm{~mm}$ were used for the research. The chemical compositions of the wires are given in table1.

Table 1. Chemical compositions of alloys (wt.\%)

\begin{tabular}{|l|c|l|l|l|l|l|}
\hline $\begin{array}{l}\text { Ti-6Al- } \\
4 \mathrm{~V}\end{array}$ & $\mathrm{C}$ & $\mathrm{Al}$ & $\mathrm{V}$ & $\mathrm{O}$ & $\mathrm{N}$ & $\mathrm{H}$ \\
\cline { 2 - 7 } & 0,63 & 6,1 & 4,2 & 0,10 & 0,03 & 0,012 \\
\hline $\begin{array}{l}\text { Inconel } \\
718\end{array}$ & $\mathrm{C}$ & $\mathrm{Ni}$ & $\mathrm{Cr}$ & $\mathrm{Nb}$ & $\mathrm{Mo}$ & $\mathrm{Ti}$ \\
\cline { 2 - 7 } & 0.07 & 53,2 & 20,4 & 5,03 & 3,12 & 1.10 \\
\hline
\end{tabular}

High-purity argon was used as a plasma-forming and protective gas.

The spraying characteristics of the studied alloys are their high affinity for oxygen and nitrogen which requires total isolation of the spraying zone and the collection of hot powder from the external environment. The powder is increased, in relation to the sprayed iron alloys, quality control of the initial-sprayed wires and preparation of containers for storing finished products.

Given that plasma spraying is mainly used to produce so-called medium powders that is powders with sizes of 40-140 microns, the percentage of powders of these fractions in the total volume of the sprayed powder mass was used as the "yield of useful" parameter.

\section{Results and discussion}

The analysis of the Ti-6Al-4V alloy spraying modes showed the best combination of the geometric quality of the obtained powders and their granulometric composition. It is achieved by using the following mode: current strength of 275 A, plasma gas velocity of 45 $\mathrm{l} / \mathrm{min}$, wire feed speed of $2.5 \mathrm{~m} / \mathrm{min}$. When these conditions are met, the high sphericity of the powders is ensured, reaching about 93-96 \%, the yield of the useful material is about $62 \%$ with an average size of powder particles $d_{50}=60-80$ microns. The proportion of powder particles with satellites, pores and other defects did not exceed $1.5 \%$.

If there is a deviation from the optimal mode, for example, with a decrease in the current supplied to the plasma torch, the percentage of useful output decreases sharply - about one and a half to two times, and the shape of the particles gradually shifts from spherical to rounded and even angular, the number of particles with satellites and other defects increases (GOST 25849-83) Fig.3.

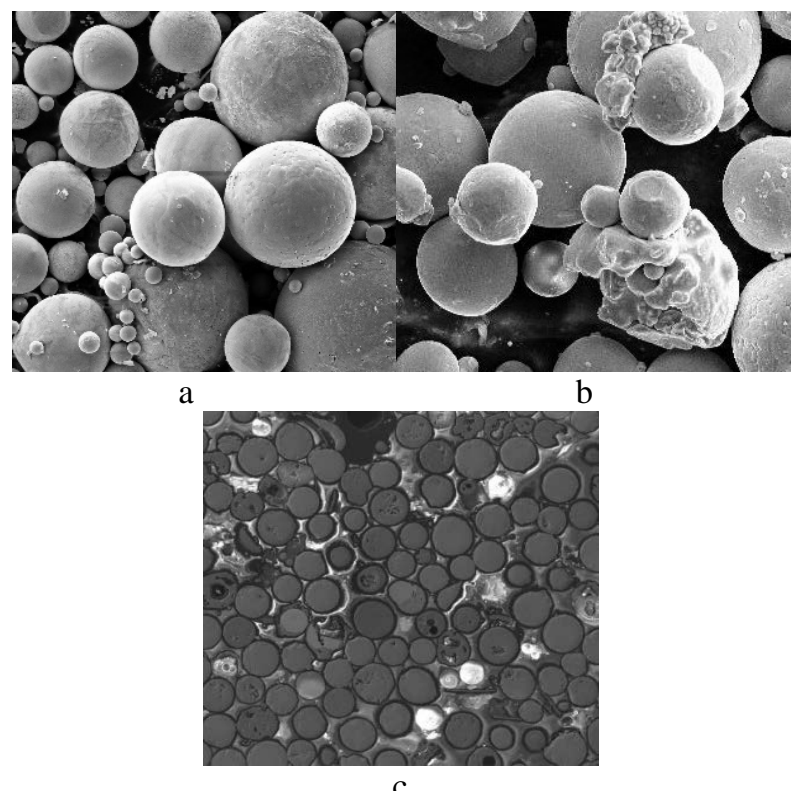

Fig.3. Particles of Ti-6Al-4V alloy powder sprayed according to the optimal mode (a) and with a deviation from it (current strength - 225 A) - an increase of x400 and (c) - a microslift of particles of the sprayed powder $\mathrm{x} 200$.

When spraying the Inconel 718 alloy wire, the optimal ratio of parameters was: current 200 A, plasma 
gas velocity $50 \mathrm{l} / \mathrm{min}$, wire feed speed $-3.75 \mathrm{~m} / \mathrm{min}$. When spraying the Inconel 718 wire according to the specified parameters, the following results were achieved: sphericity of $95-97 \%$, yield of at least $64 \%$ with an average size of powder particles d50 $=60-75$ microns, the proportion of powder particles with various defects - no more than $1.0 \%$. (Fig. 4). Deviations from the optimal mode, as well as in the case of a titanium alloy, lead to a decrease in the yield of the useful powder and a deterioration in the geometric quality of the resulting powder.

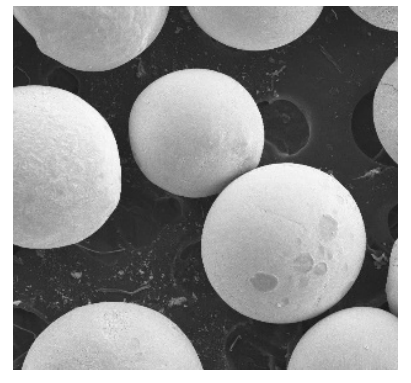

a

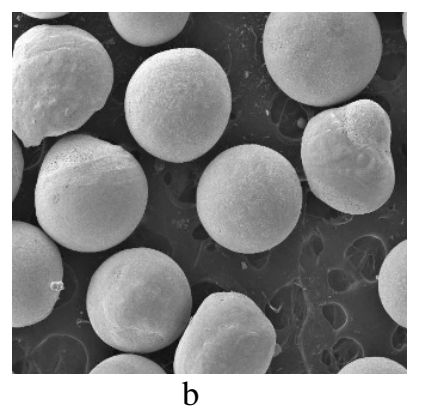

b
Fig.4. Ti-6Al-4V alloy powder particles sprayed according to the optimal mode (a) and with a deviation from it (current - 170 A), magnification $\mathrm{x} 400$.

Thus, it was shown that plasma spraying provides a satisfactory yield percentage of commercial powder fractions - at the level of $60-65 \%$ of the mass of the sprayed metal. It allows to get powders with a minimum number of surface and internal defects, geometric shapes, granulometric composition of which allows them to be used in additive manufacturing. However, in addition to the geometric parameters of the powder quality it is necessary to confirm their chemical compliance with the sprayed materials. For this purpose, comparative studies of the chemical compositions of the initial wires and the resulting powders were carried out.

As an example, Fig. 5 shows the results of chemicalspectral control of the wire and the powder particles of the Ti-6Al-4V alloy.

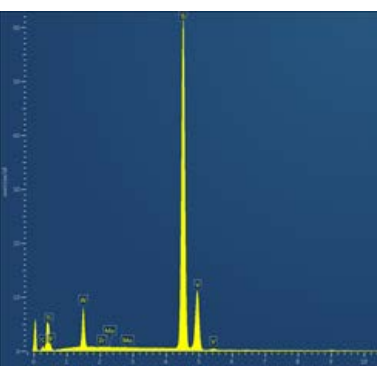

a

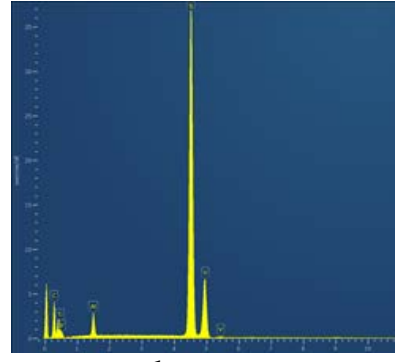

b
Fig.5. Spectral analysis results of the initial wire (a) and the atomized powder (b) of the Ti-6Al-4V alloy.

Given the high affinity of the studied alloys to oxygen and other light impurities, special attention was paid to the change in the concentration of elements such as carbon, oxygen, nitrogen, and hydrogen during the chemical analysis.

It was found that the content of the main alloying elements and carbon in both alloys practically did not change during the wire spraying process. The results of the analysis of the gas content in the sprayed powder particles allow us to conclude that while ensuring the proper quality of the protective gas atmosphere in the spray column and in the powder collection system, their concentration does not exceed the level of requirements for the starting materials.

So, for example, the limiting concentration of oxygen in the Ti-6Al-4V alloy (ASTM F136-02a) is 0.13 wt.\%, in the initial wire -0.102 and in the powder -0.109 wt.\%; nitrogen - 0.05, 0.033 and 0.038 wt.\%, respectively, of hydrogen $-0.012,0.009$ and 0.011 wt.\%.

Thus, it was confirmed that plasma spraying does not lead to any significant changes in the chemical composition of the sprayed powders.

The most important indicator of the quality of powders, by which it is possible to confirm the legality of their use in the production of products using additive technologies, is the mechanical properties of samples made from them. For this purpose, using Selective Laser Melting (SLM) methods, proportional flat samples of type II GOST 1497-84 were made from sprayed powders.

Table 2 shows the mechanical properties results of samples made from sprayed powders. For comparison, the same table provides data on the regulatory requirements for the mechanical properties of compact alloys. For the Ti-6Al-4V alloy, these are the requirements of ASTM F136 and GOST R ISO 5832-32020, for the Inconel 718 alloy API Standard 6A718.

The heat treatment of the obtained samples was performed in accordance with the requirements of the regulatory documentation for these materials.

Table 2. Mechanical properties of samples at $20^{\circ} \mathrm{C}$

\begin{tabular}{|c|c|c|c|c|}
\hline \multicolumn{2}{|c|}{ Alloy } & $\sigma_{\mathrm{B}}$ & $\sigma_{0,2}$ & $\delta_{5}$ \\
\cline { 2 - 5 } & \multicolumn{3}{|c|}{$\mathrm{MPa}$} & $\%$ \\
\hline Ti-6Al-4V & $1^{*}$ & 885 & 820 & 12 \\
\cline { 2 - 5 } & 2 & 860 & 795 & 10 \\
\hline Inconel 718 & 1 & 165 & 124 & 18 \\
\cline { 2 - 5 } & 2 & 145 & 122 & 17 \\
\hline
\end{tabular}

Table 2 analysis confirms that the mechanical properties of samples made from sprayed powders by the SLM method meet the requirements for these alloys.

Based on the conducted experiments, it was shown that the method of plasma spraying of alloys with a high affinity for oxygen allows us to obtain high-quality spherical powders suitable for use in additive machines of various types.

\section{Conclusions}

1. Plasma atomization is found to obtain high-quality powders of nickel and titanium alloys, suitable for use in 
additive machines of various types. The powders have a high degree of sphericity, the chemical composition of the obtained powders practically did not differ from the compositions of the original feedstock, the proportion of powders with surface and internal defects does not exceed $1.0-1.5 \%$.

2. The basic energy-power parameters of atomization of titanium and nickel alloy wires, which provide the maximum percentage of the yield of commodity fractions of powders of the studied alloys, are determined.

3. The mechanical properties of products obtained by SLM methods from pulverized powders were shown to meet the requirements for these alloys manufactured and heat-treated according to traditional technologies.

\section{References}

1. E.N. Kablov, Metals of Eurasia, 3, 3-21 (2017)

2. M.A. Zlenko, A.A. Popovich, I.N. Mutylina, St. Petersburg. Polytechnic University Press, 221 (2013)

3. M.Yu. Gryaznov, S.V. Shotin, V.N. Chuvildeev, Solid state physics. Vestnik Nizhegorodskogo universiteta im. n. I. Lobachevsky, 4(1), 46-51 (2014)

4. T. Wohlers, Wohlers Report 2014: Additive Manufacturing and 3D Printing State of the Industry (Annual Worldwide Progress Report. Wohlers Associates Inc., 2014)

ISBN 978-0-991333-2-6-4

5. A. Uriondo, M. Esperon-Miguez, S. Perinpanayagam, Proceedings of the Institution of Mechanical Engineers. Part G: Journal of Aerospace Engineering, 229(11), 2132-2147 (2015) DOI: 10.18721

6. B.S. Ermakov, S.B. Ermakov, A. Pavlenko, S.A. Vologzhanina, IOP Conference Series: Materials Science and Engineering, 826, 012007 (2020)

DOI 10.1088

7. B.S. Ermakov, S.B. Ermakov, M.A. Odnoblyudov, V.G. Teplukhin, Development of equipment for obtaining metal powders for additive technologies. New technologies for equipment and structures of the North and the Arctic (Proceedings of the International Conference. Yakutsk, NEFU Publishing House, 2016)

8. A.A. Popovich, Mechanochemical synthesis of refractory compounds. Ministry of Education of the Russian Federation, Far Eastern State Technical University (DVPI named after V. V. Kuibyshev) (Vladivostok: Publishing House of DVSTU, 2003) 